Archives

$43 \mid 2009$

Hommage à Jacques Ozouf

\title{
Articles de Jacques Ozouf dans l'«Observateur » : France Observateur et Nouvel Observateur 1958-1977
}

\section{Quentin Deluermoz}

\section{Q OpenEdition}

\section{Journals}

Édition électronique

URL : http://journals.openedition.org/ccrh/3626

DOI : $10.4000 /$ ccrh.3626

ISSN : $1760-7906$

\section{Éditeur}

Centre de recherches historiques - EHESS

Édition imprimée

Date de publication : 25 janvier 2009

ISSN : 0990-9141

Référence électronique

Quentin Deluermoz, «Articles de Jacques Ozouf dans I'« Observateur »: France Observateur et Nouvel Observateur 1958-1977 », Les Cahiers du Centre de Recherches Historiques [En ligne], 43 | 2009, mis en ligne le 20 février 2012, consulté le 21 avril 2019. URL : http://journals.openedition.org/ccrh/3626 ; DOl : $10.4000 /$ ccrh.3626

Ce document a été généré automatiquement le 21 avril 2019

Article L.111-1 du Code de la propriété intellectuelle. 


\title{
Articles de Jacques Ozouf dans l'«Observateur»: France Observateur et Nouvel Observateur 1958-1977
}

\author{
Quentin Deluermoz
}

Tableaux établis et réalisés par Quentin Deluermoz

Rythmes

\begin{tabular}{|l|l|l|l|l|l|l|l|l|l|l|l|l|l|}
\hline 1965 & 1966 & 1967 & 1968 & 1969 & 1970 & 1971 & 1972 & 1973 & 1974 & 1975 & 1976 & $1977^{*}$ & 1981 \\
\hline 3 & 3 & 2 & 3 & 15 & 13 & 4 & 9 & 13 & 16 & 15 & 19 & 9 & 1 \\
\hline
\end{tabular}

*jusque fin mai

Rubriques

\begin{tabular}{|l|l|}
\hline Événement & 62 \\
\hline Lettres arts spectacles & 33 \\
\hline Notre couverture & 15 \\
\hline Notre époque & 5 \\
\hline Document de la semaine & 8 \\
\hline Total & 123 \\
\hline
\end{tabular}


Les articles de Jacques Ozouf dans le Nouvel Observateur, 1965-1977'

\section{Présentation détaillée}

\begin{tabular}{|c|c|c|c|c|c|c|}
\hline Année & $\mathrm{N}^{\circ} /$ mois & Titre & Taille & Rubrique & $\begin{array}{l}\text { Illustration } \\
\text { Document }\end{array}$ & $\begin{array}{l}\text { Nature / } \\
\text { (Événement politique de } \\
\text { référence) }\end{array}$ \\
\hline \multirow{3}{*}{1965} & $\begin{array}{l}\mathrm{n}^{\circ} 18 \\
\text { mars } 1965\end{array}$ & $\begin{array}{l}\text { "La France de M. } \\
\text { Pradel " avec F. } \\
\text { Delcroix (F. Furet) }\end{array}$ & & «Événement » & & $\begin{array}{l}\text { Analyse de scrutin des } \\
\text { élections municipales, } 1^{\mathrm{er}} \\
\text { tour } \\
\text { (élections municipales 1965) }\end{array}$ \\
\hline & $\begin{array}{l}\mathrm{n}^{\circ} 19 \\
\text { mars } 1965\end{array}$ & $\begin{array}{l}\text { «Tableau du } \\
\text { scrutin à Paris » }\end{array}$ & 2 pages & « Événement » & & $\begin{array}{l}\text { Tableau commenté du } \\
\text { vote de droite à Paris - } \\
\text { accompagne le } \\
\text { commentaire de } \\
\text { Delcroix, «Les deux } \\
\text { droites" } \\
\text { (élections municipales 1965) }\end{array}$ \\
\hline & $\begin{array}{l}\mathrm{n}^{\circ} \quad 58 \\
\text { décembre } \\
1965\end{array}$ & « Le suris» & 2 pages & $\begin{array}{l}\text { «Événement» } \\
\text { sous rubrique } \\
\text { «Analyse» }\end{array}$ & 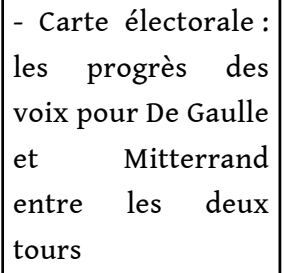 & $\begin{array}{l}\text { Analyse d'élection } \\
\text { présidentielle, résultat } \\
\text { du deuxième tour } \\
\text { (élections présidentielles } \\
\text { 1965, après le } 2^{e} \text { tour) }\end{array}$ \\
\hline \multirow[b]{2}{*}{1966} & $\begin{array}{l}\mathrm{n}^{\circ} 72 \\
\text { avril } 1966\end{array}$ & $\begin{array}{l}\text { «Le tour de } \\
\text { France des } \\
\text { présidentielles }\end{array}$ & 1 page & $\begin{array}{l}\text { « Lettres-arts- } \\
\text { spectacles» (Laspe) }\end{array}$ & $\begin{array}{l}3 \text { photos: } \\
\text { - Un meeting pour } \\
\text { F. Mitterrand. (« } \\
\text { Que faut-il retenir? } \\
») \\
\text { - J-F. Revel («Le } \\
\text { cirque... ») } \\
\text { - G. Suffert («.... Ou } \\
\text { Defferre?») }\end{array}$ & $\begin{array}{l}\text { Compte rendu de } \\
2 \text { ouvrages: } \\
\text { - G. Suffert, De Defferre à } \\
\text { Mitterrand, Seuil } \\
\text { - J-F. Revel M. Cotta, Les } \\
\text { élections présidentielles de } \\
1965 \\
\text { (élections présidentielles } \\
\text { 1965, après le } 2^{e} \text { tour) }\end{array}$ \\
\hline & $\begin{array}{l}\mathrm{n}^{\circ} 79 \\
\text { mai } 1966\end{array}$ & $\begin{array}{l}\text { «La course à } \\
\text { l'Élysée " }\end{array}$ & 1 page & Laspe & $\begin{array}{l}2 \text { photos: } \\
\text { - J. Derogy } \\
\text { - J-F Kahn } \\
\text { Légende pour les } 2 \\
: \text { « De l'intérieur» }\end{array}$ & $\begin{array}{l}\text { Compte rendu d'ouvrage } \\
\text { - J. Derogy J-F. Kahn, Les } \\
\text { secrets du ballotage, } \\
\text { Fayard } \\
\text { (élections présidentielles } \\
\text { 1965, après le } 2^{e} \text { tour) }\end{array}$ \\
\hline
\end{tabular}




\begin{tabular}{|c|c|c|c|c|c|c|}
\hline & $\begin{array}{l}\mathrm{n}^{\circ} \quad 102 \\
\text { octobre } \\
1966\end{array}$ & $\begin{array}{l}\text { "Les catholiques } \\
\text { français ont-ils } \\
\text { changés?" }\end{array}$ & 2 pages & $\begin{array}{l}\text { "Notre Époque " } \\
\text { Dans un gros } \\
\text { dossier: } \\
\text { "Comment vous } \\
\text { êtes catholiques ", } \\
\text { par M. Bergoin, C } \\
\text { Hebert, } \\
\text { J. Ozouf } \\
\text { (Annoncé } \\
\text { couverture) }\end{array}$ & $\begin{array}{l}\text { Plusieurs photos } \\
\text { - Différents } \\
\text { Monseigneurs, } \\
\text { - R. Garaudy, } \\
\text { - C. Maurras. } \\
\text { Sur les côtés : } 8 \\
\text { tableaux de } \\
\text { sondages }\end{array}$ & $\begin{array}{l}\text { Analyse de sondage IFOP } \\
\text { sur les comportements } \\
\text { politiques des } \\
\text { catholiques }\end{array}$ \\
\hline \multirow{3}{*}{1967} & $\begin{array}{l}\mathrm{n}^{\circ} 121 \\
\text { mars } 1967\end{array}$ & $\begin{array}{l}\text { «La droite } \\
\text { retrouve l'ordre " }\end{array}$ & 3 pages & $\begin{array}{l}\text { «Événement » } \\
\text { «spécial élections » }\end{array}$ & Tableaux & $\begin{array}{l}\text { Analyse du premier tour } \\
\text { des élections législatives } \\
\text { (élections législatives } 19671 \\
\text { er tour) }\end{array}$ \\
\hline & $\begin{array}{l}\mathrm{n}^{\circ} 122 \\
\text { mars } 1967\end{array}$ & $\begin{array}{l}\text { "Sursis pour une } \\
\text { majorité " }\end{array}$ & 2 pages & « Événement » & $\begin{array}{l}\text { Plusieurs photos } \\
(\ldots)\end{array}$ & $\begin{array}{l}\text { Analyse du second tour } \\
\text { des élections législatives } \\
\text { (élections législatives } 1967,2 \\
{ }^{e} \text { tour) }\end{array}$ \\
\hline & $\begin{array}{l}n^{\circ} 131 \\
\text { Mai } 1967\end{array}$ & & & & & $\begin{array}{l}\text { Compte rendu de « Nous } \\
\text { les maîtres d'école", par } \\
\text { J. Julliard. }\end{array}$ \\
\hline \multirow{3}{*}{1968} & $\begin{array}{l}n^{\circ} 184 \\
\text { Mai } 1968\end{array}$ & $\begin{array}{l}\text { "Université : } \\
\text { passeront-ils les } \\
\text { examens » }\end{array}$ & 1,5 page & $\begin{array}{lr}\text { Pas de rubrique } \\
\text { pendant } & \text { les } \\
\text { "événements } & \text { de } \\
68 & \end{array}$ & $\begin{array}{l}\text { Pas d'illustration } \\
\text { (aucune pendant } \\
\text { les «événements " } \\
\text { de 68) }\end{array}$ & \\
\hline & $\begin{array}{l}n^{\circ} 189- \\
\text { Juin } 1968\end{array}$ & $\begin{array}{l}\text { "Spécial } \\
\text { élections : la } \\
\text { France de pépé » }\end{array}$ & 2 pages & «Événement » & $\begin{array}{l}\text { Tableau : les } \\
\text { déplacements des } \\
\text { voix entre } 1967 \text { et } \\
1968\end{array}$ & $\begin{array}{l}\text { Analyse du premier tour } \\
\text { des élections législatives. } \\
\text { (élections législatives 1968, } 1 \\
\text { er tour) }\end{array}$ \\
\hline & $\begin{array}{l}\mathrm{n}^{\circ} 190 \\
\text { Juin } 1968\end{array}$ & $\begin{array}{l}\text { "L'analyse du } \\
\text { second tour : à qui } \\
\text { la faute", avec F. } \\
\text { Furet }\end{array}$ & 1,5 page & « Événement » & Tableau & $\begin{array}{l}\text { Analyse du second tour } \\
\text { des élections législatives. } \\
\text { (élections législatives } 1968,2 \\
{ }^{e} \text { tour) }\end{array}$ \\
\hline
\end{tabular}




\begin{tabular}{|c|c|c|c|c|c|c|}
\hline \multirow{3}{*}{1969} & $\begin{array}{l}\mathrm{n}^{\circ} 217 \\
\text { janvier } \\
1969\end{array}$ & $\begin{array}{l}\text { "Les communistes } \\
\text { et leur monde» }\end{array}$ & 1 page & $\begin{array}{l}\text { Laspe. Dans un } \\
\text { dossier : «la longue } \\
\text { nuit stalinienne », } \\
\text { texte } n^{\circ} 4\end{array}$ & $\begin{array}{l}2 \text { Photos : } \\
\text { - Marcel Cachin et } \\
\text { Maurice Thorez en } \\
1938 \text { ( "L'héritage } \\
\text { jacobin et le } \\
\text { modèle } \\
\text { bolchevik») } \\
\text { - Annie Kriegel } \\
\text { (« Un ton de } \\
\text { connivence ") }\end{array}$ & $\begin{array}{l}\text { Compte rendu } \\
\text { d'ouvrage: } \\
-\quad \text { A. Kriegel, Les } \\
\text { communistes français, } \\
\text { Seuil }\end{array}$ \\
\hline & $\begin{array}{l}\mathrm{n}^{\circ} \quad 223 \\
\text { février } \\
1969\end{array}$ & $\begin{array}{ll}\text { «Histoire : les } \\
\text { intrigues de la } \mathrm{IV}^{\mathrm{e}} \\
»\end{array}$ & 1 page & Laspe & $\begin{array}{l}2 \text { photos: } \\
\text { - Dien Bien Phu } \\
\text { - Joseph Laniel } \\
\text { ( des bulletins } \\
\text { douteux») }\end{array}$ & $\begin{array}{ll}\text { Compte } & \text { rendu } \\
\text { d'ouvrage: } & \\
\text { - G. Elgey, } & \text { La République } \\
\text { des } & \text { contradictions } \\
(1951-1954) », & \text { Fayard }\end{array}$ \\
\hline & $\begin{array}{l}\mathrm{n}^{\circ} 226 \\
\operatorname{mars} 1969\end{array}$ & Pas de titre & 1,5 page & $\begin{array}{lr}\text { Laspe } & \\
\text { Rubrique } & \text { "D'un } \\
\text { auteur } & \text { l'autre " } \\
\text { (petits } & \text { comptes } \\
\text { rendus) } & \end{array}$ & $\begin{array}{l}\text { Deux photos: } \\
\text { - Alain Lancelot et } \\
\text { la couverture de } \\
\text { son livre } \\
\text { - André Fontaine }\end{array}$ & 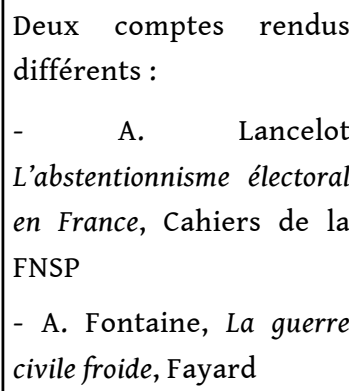 \\
\hline \multirow[t]{3}{*}{1969} & $\begin{array}{l}\mathrm{n}^{\circ} 232 \\
\text { avril } 1969\end{array}$ & $\begin{array}{l}\text { «Sondage : ce que } \\
\text { les } \quad \text { Français } \\
\text { pensent de la } \\
\text { participation » }\end{array}$ & 2 pages & "Événement » & $\begin{array}{llr}1 \quad \text { page } & \text { de } & 5 \\
\text { tableaux } & & \text { de } \\
\text { résultats } & & \end{array}$ & $\begin{array}{l}\text { Analyse de sondage } \\
\text { Sofres } \\
\text { Préparation du referendum }\end{array}$ \\
\hline & $\begin{array}{l}n^{\circ} 233 \\
\text { avril } 1969\end{array}$ & $\begin{array}{l}\text { "Ceux qui l'ont } \\
\text { lâché » }\end{array}$ & 1 page & $\begin{array}{l}\text { «Événement » } \\
\text { «Spécial résultat » }\end{array}$ & Pas d'illustration & $\begin{array}{l}\text { Analyse des résultats du } \\
\text { referendum }\end{array}$ \\
\hline & $\begin{array}{l}\mathrm{n}^{\circ} 235 \\
\text { mai } 1969\end{array}$ & \begin{tabular}{|ll} 
"Portrait: & un \\
"gaulliste " & en \\
quelque sorte " &
\end{tabular} & 1 page & Laspe & $\begin{array}{l}\text { Photo Georges } \\
\text { Pompidou à } 16 \text { ans. } \\
\text { «Son secret, c'est } \\
\text { de ne pas en } \\
\text { avoir» }\end{array}$ & $\begin{array}{l}\text { Compte rendu } \\
\text { d'ouvrage: } \\
\text { - P. Rouanet, Pompidou, } \\
\text { Grasset }\end{array}$ \\
\hline
\end{tabular}




\begin{tabular}{|c|c|c|c|c|c|}
\hline $\begin{array}{l}\mathrm{n}^{\circ} 238 \\
\text { juin } 1969\end{array}$ & $\begin{array}{l}\text { «Les révélations } \\
\text { du premier tour» }\end{array}$ & 1 page & «Événement» & $\begin{array}{l}2 \text { photos : } \\
\text { - C. et G Pompidou } \\
\text { votant à Orvilliers. } \\
\text { «Des velléités } \\
\text { réformistes } \\
\text { troqués contre } \\
\text { l'immobilisme } \\
\text { réactionnaire. " } \\
\text { - A. Poher à Ablon. } \\
\text { « Le noyau n'était } \\
\text { pas intact. » }\end{array}$ & $\begin{array}{l}\text { Analyse du premier tour } \\
\text { des élections } \\
\text { présidentielles } \\
\text { (élections présidentielles } \\
1969,1^{\text {er }} \text { tour) }\end{array}$ \\
\hline $\begin{array}{l}\mathrm{n}^{\circ} 240 \\
\text { juin } 1969\end{array}$ & $\begin{array}{l}\text { «Le second tour. } \\
\text { De l'immobilisme à } \\
\text { l'immobilier" }\end{array}$ & 1,5 page & «Événement » & $\begin{array}{l}\text { Photo: } \\
\text { - Jacques Duclos le } \\
\text { jour du second } \\
\text { tour. "Au-delà de } \\
\text { toutes les } \\
\text { espérances» }\end{array}$ & $\begin{array}{l}\text { Analyse du second tour } \\
\text { des élections } \\
\text { présidentielles } \\
\text { (élections présidentielles } \\
1969,2^{e} \text { tour) }\end{array}$ \\
\hline $\begin{array}{l}n^{\circ} 243 \\
\text { juillet } \\
1969\end{array}$ & $\begin{array}{l}\text { "Essai : quatre } \\
\text { médecins pour la } \\
\text { gauche» }\end{array}$ & 1 page & Laspe & $\begin{array}{l}4 \text { photos : } \\
\text { - F. Mitterrand } \\
\text { «Tous plus } \\
\text { obsédés... » } \\
\text { - M. Rocard " par } \\
\text { leurs cousins... " } \\
\text { - A. Krivine "... } \\
\text { politiques... » } \\
\text { - J. Poperen "... } \\
\text { que par leurs } \\
\text { ennemis » }\end{array}$ & $\begin{array}{l}\text { Compte rendu de } \\
\text { ouvrages: } \\
\text { - A. Krivine, La farce } \\
\text { électorale, Le Seuil } \\
\text { - F. Mitterrand, Ma part } \\
\text { de vérité. De la rupture à } \\
\text { l'unité, Fayard } \\
\text { - J. Poperen, Une stratégie } \\
\text { pour la gauche, Fayard } \\
\text { M. Rocard, Le PSU et } \\
\text { l'avenir socialiste de la } \\
\text { France, Le Seuil }\end{array}$ \\
\hline $\begin{array}{l}\mathrm{n}^{\circ} 247 \\
\text { août } 1969\end{array}$ & $\begin{array}{l}\text { "Politique : } \\
\text { bonnet rouge et } \\
\text { blanc bonnet» }\end{array}$ & 1 page & Laspe & 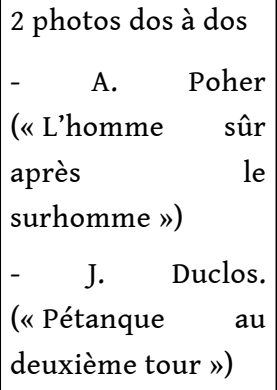 & $\begin{array}{l}\text { Compte rendu de } \\
\text { 2ouvrages: } \\
\text { - D. Pado, Les } 50 \text { jours } \\
\text { d'Alain Poher, Denoël } \\
\text { - R. Lechêne, Tambour } \\
\text { battant. La campagne } \\
\text { électorale de J. Duclos, } \\
\text { Fayard }\end{array}$ \\
\hline $\begin{array}{l}n^{\circ} 258 \\
\text { octobre } \\
1969\end{array}$ & Pas de titre & 1 page & $\begin{array}{l}\text { Laspe } \\
\text { Rubrique «d'un } \\
\text { auteur l'autre » }\end{array}$ & Pas d'illustrations & $\begin{array}{l}\text { Compte rendu } \\
\text { d'ouvrage: } \\
\text { - J. Moche, Destin de la } \\
\text { paix, Mercure de France }\end{array}$ \\
\hline
\end{tabular}




\begin{tabular}{|c|c|c|c|c|}
\hline $\begin{array}{l}\text { «Histoire: les } \\
\text { soldats de Pétain » }\end{array}$ & 2 pages & Laspe & $\begin{array}{l}\text { Photo } \\
\text { - Jacques Darnand, } \\
\text { tenue militaire, } \\
\text { salut militaire.(« Le } \\
\text { héros était aigri ») }\end{array}$ & $\begin{array}{ll}\text { Compte } & \text { rendu } \\
\text { d'ouvrage: } & \\
\text { - J. Delperrié de Bayac } \\
\text { Histoire de la } \\
\text { (1918-1945, Fayard }\end{array}$ \\
\hline Pas de titre & 1 page & $\begin{array}{l}\text { Laspe } \\
\text { Rubrique «D'un } \\
\text { auteur l'autre» }\end{array}$ & Pas d'illustrations & $\begin{array}{l}\text { Compte rendu } \\
\text { d'ouvrage: } \\
\text { - c. Hernu, Priorité à } \\
\text { gauche, Denoël }\end{array}$ \\
\hline $\begin{array}{l}\text { «Clefs pour le } \\
\text { PSU » }\end{array}$ & 10 pages & $\begin{array}{l}\text { «Document de la } \\
\text { semaine» }\end{array}$ & $\begin{array}{l}\text { Photos, tableaux } \\
\text { etc. }\end{array}$ & $\begin{array}{l}\text { Début d'une série de } \\
\text { «Document de la } \\
\text { semaine» analysant les } \\
\text { forces politiques de } \\
\text { gauche }\end{array}$ \\
\hline $\begin{array}{l}\text { "Actualités : } \\
\text { L'évènement au } \\
\text { triple galop " }\end{array}$ & 1 page & $\begin{array}{l}\text { "Événement ", } \\
\text { encadré }\end{array}$ & Pas d'illustrations & $\begin{array}{l}\text { Inclus dans une série } \\
\text { d'articles qui font le } \\
\text { point sur vingt ans de } \\
\text { Nouvel } \\
\text { 1950-1970 Observateur }\end{array}$ \\
\hline $\begin{array}{l}\text { «Ce qui change } \\
\text { chez les } \\
\text { communistes» }\end{array}$ & 7 pages & $\begin{array}{l}\text { "Document de la } \\
\text { semaine» }\end{array}$ & $\begin{array}{l}\text { Photos, tableaux, } \\
\text { encarts... }\end{array}$ & $\begin{array}{l}\text { Suite de la série de } \\
\text { «Document de la } \\
\text { semaine analysant les } \\
\text { forces politiques de } \\
\text { gauche }\end{array}$ \\
\hline Pas de titre & 1 page & $\begin{array}{l}\text { Laspe } \\
\text { Rubrique «D'un } \\
\text { auteur l'autre» }\end{array}$ & $\begin{array}{l}\text { Photos des auteurs } \\
\text { et de la couverture } \\
\text { des ouvrages }\end{array}$ & $\begin{array}{l}\text { Compte rendu de } 2 \\
\text { ouvrages: } \\
\text { - A. Barjonet, Le parti } \\
\text { communiste français, } \\
\text { Didier } \\
\text { - A. Kriegel, Aux origines } \\
\text { du communisme français, } \\
\text { Flammarion }\end{array}$ \\
\hline
\end{tabular}




\begin{tabular}{|c|c|c|c|c|c|}
\hline $\begin{array}{l}\mathrm{n}^{\circ} 279 \\
\text { mars } 1970\end{array}$ & $\begin{array}{l}\text { «Cantonales: les } \\
\text { «jeunes loups » et } \\
\text { les vieux } \\
\text { notables» }\end{array}$ & 2 pages & « Événement » & $\begin{array}{l}\text { Photo: Un bulletin } \\
\text { de vote } \\
\text { (« Dépouillement } \\
\text { du scrutin. Une } \\
\text { photographie de } \\
\text { l'opinion } \\
\text { française ») } \\
\text { Un encart "Les } \\
\text { notables » avec un } \\
\text { tableau de l'origine } \\
\text { sociale des } 96 \\
\text { conseillers } \\
\text { régionaux } \\
\text { Franche-Comté }\end{array}$ & $\begin{array}{l}\text { Analyse des résultats des } \\
\text { élections cantonales } \\
\text { (élections cantonales 1970) }\end{array}$ \\
\hline $\begin{array}{l}\mathrm{n}^{\circ} 280 \\
\text { mars } 1970\end{array}$ & Pas de titre & 1 page & $\begin{array}{l}\text { «Événement " } \\
\text { Rubrique «on en } \\
\text { parlera demain » }\end{array}$ & Pas d'illustrations & $\begin{array}{l}\text { Succession de comptes } \\
\text { rendus dont les auteurs } \\
\text { sont présentés } \\
\text { collectivement. }\end{array}$ \\
\hline $\begin{array}{l}\mathrm{n}^{\circ} 280 \\
\text { mars } 1970\end{array}$ & Pas de titre & 1 page & $\begin{array}{l}\text { Laspe } \\
\text { Rubrique «D'un } \\
\text { auteur l'autre » }\end{array}$ & $\begin{array}{l}\text { Photo de l'auteur } \\
\text { et de la couverture } \\
\text { de l'ouvrage }\end{array}$ & $\begin{array}{l}\text { Compte rendu } \\
\text { d'ouvrage: } \\
\text { - F. Goguel, Modernisation } \\
\text { économique et } \\
\text { comportement électoral, A. } \\
\text { Colin }\end{array}$ \\
\hline $\begin{array}{l}\mathrm{n}^{\circ} 283 \\
\text { avril } 1970\end{array}$ & $\begin{array}{l}\text { «Il y a } 20 \text { ans, } \\
\text { l'Observateur », par } \\
\text { G. Martinet } \\
\text { (historique du } \\
\text { journal) }\end{array}$ & & & & \\
\hline $\begin{array}{l}\mathrm{n}^{\circ} 291 \\
\text { mai } 1970\end{array}$ & $\begin{array}{l}\text { «Essai : la } \\
\text { deuxième mort de } \\
\text { Charles de Gaulle » }\end{array}$ & 1,5 page & «Événement » & $\begin{array}{l}\text { Caricature de De } \\
\text { Gaulle par D. } \\
\text { Lévine }\end{array}$ & $\begin{array}{l}\text { Compte-rendu } \\
\text { d'ouvrage: } \\
\text { - J. Charlot, Le phénomène } \\
\text { gaulliste }\end{array}$ \\
\hline $\begin{array}{l}\mathrm{n}^{\circ} 292 \\
\text { juin } 1970\end{array}$ & $\begin{array}{l}\text { «Le pari téméraire } \\
\text { d'Alain Savary » }\end{array}$ & 7 pages & $\begin{array}{l}\text { «Document de la } \\
\text { semaine" }\end{array}$ & $\begin{array}{l}\text { Photos, tableaux, } \\
\text { encarts... }\end{array}$ & $\begin{array}{l}\text { Suite de la série de } \\
\text { «Document de la } \\
\text { semaine " analysant les } \\
\text { forces politiques de } \\
\text { gauche }\end{array}$ \\
\hline $\begin{array}{l}\mathrm{n}^{\circ} 301 \\
\text { août } 1970\end{array}$ & Pas de titre & 1 page & $\begin{array}{l}\text { Laspe } \\
\text { Rubrique «D'un } \\
\text { auteur l'autre » }\end{array}$ & Pas d'illustration & $\begin{array}{l}\text { Compte } \\
\text { d'ouvrage: } \\
\text { Freyssinet-Dominjon Les } \\
\text { manuels de l'école libre } \\
\text { (1882-1959), A. Colin }\end{array}$ \\
\hline
\end{tabular}




\begin{tabular}{|c|c|c|c|c|c|}
\hline $\begin{array}{l}\mathrm{n}^{\circ} 304 \\
\text { septembre } \\
1970\end{array}$ & Pas de titre & 1 page & $\begin{array}{l}\text { Laspe } \\
\text { Rubrique «d'un } \\
\text { auteur l'autre» }\end{array}$ & $\begin{array}{l}\text { Photo auteur et } \\
\text { couverture }\end{array}$ & $\begin{array}{l}\text { Compte rendu } \\
\text { d'ouvrage: } \\
\text { - R. Paranque, Le malaise } \\
\text { français, Le Seuil }\end{array}$ \\
\hline $\begin{array}{l}\mathrm{n}^{\circ} 308 \\
\text { octobre } \\
1970\end{array}$ & $\begin{array}{l}\text { «Politique : les } \\
\text { «micmacs de la } \mathrm{V}^{\mathrm{e}} \\
\text { " }\end{array}$ & 1 page & Laspe & Pas d'illustration & $\begin{array}{l}\text { Compte rendu } \\
\text { d'ouvrage: } \\
\text { - P. Alexandre, Le duel DG- } \\
\text { Pompidou, Grasset }\end{array}$ \\
\hline $\begin{array}{l}\mathrm{n}^{\circ} 312 \\
\text { novembre } \\
1970\end{array}$ & $\begin{array}{l}\text { "Histoire : un } \\
\text { suicide } \\
\text { inexplicable" }\end{array}$ & 1 page & Laspe & 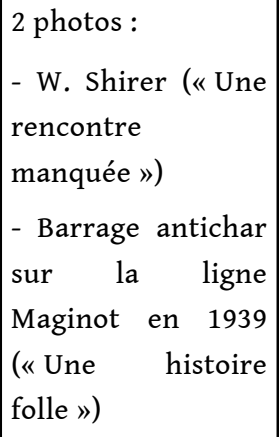 & $\begin{array}{l}\text { Compte rendu } \\
\text { d'ouvrage : } \\
\text { - W. Shirer, La chute de la } \\
\text { Troisième République, } \\
\text { Stock }\end{array}$ \\
\hline $\begin{array}{l}\mathrm{n}^{\circ} 314 \\
\text { novembre } \\
1970\end{array}$ & « Elle et lui » & 1 page & $\begin{array}{l}\text { "Événement " (sur } \\
\text { l'héritage de De } \\
\text { Gaulle) }\end{array}$ & $\begin{array}{l}2 \text { photos : } \\
\text {-La gauche défilant } \\
\text { en mai 1958 («Le } \\
\text { combat des mêmes } \\
\text { contre les } \\
\text { mêmes ») } \\
\text { - La droite défilant } \\
\text { sur les Champs- } \\
\text { Elysées en mai } 68 \\
\text { («L'héritage } \\
\text { empoché et le } \\
\text { testateur } \\
\text { renvoyé ») }\end{array}$ & $\begin{array}{l}\text { Analyse historique et } \\
\text { politique des rapports } \\
\text { entre la gauche et De } \\
\text { Gaulle. } \\
\text { (Départ de De Gaulle) }\end{array}$ \\
\hline $\begin{array}{l}\mathrm{n}^{\circ} 320 \\
\text { décembre } \\
1970 \\
\text { suite } \mathrm{n}^{\circ} \\
320\end{array}$ & $\begin{array}{l}\text { "Histoire : un } \\
\text { mauvais Tours " }\end{array}$ & 1 page & $\begin{array}{l}\text { Laspe, rubrique } \\
\text { « Histoire » }\end{array}$ & $\begin{array}{l}\text { Photo: } \\
\text { - Les congressistes } \\
\text { de Tours («Une } \\
\text { douloureuse } \\
\text { opération } \\
\text { chirurgicale ») }\end{array}$ & $\begin{array}{l}\text { Compte rendu } \\
\text { d'ouvrage : } \\
\text { - J. Fréville, La nuit finit à } \\
\text { Tours, Les Éditions } \\
\text { sociales }\end{array}$ \\
\hline
\end{tabular}




\begin{tabular}{|c|c|c|c|c|c|c|}
\hline & $\begin{array}{l}\mathrm{n}^{\circ} 329 \\
\text { mars } 1971\end{array}$ & $\begin{array}{l}\text { «Nation: l'enjeu } \\
\text { des municipales » }\end{array}$ & $\begin{array}{ll}1, & 5 \\
\text { pages }\end{array}$ & «Événement » & $\begin{array}{l}\text { - Une caricature : } \\
\text { un camion à } \\
\text { ordures entouré de } \\
\text { laquais en grande } \\
\text { tenue («Un peu } \\
\text { plus d'apparat } \\
\text { dans la vie } \\
\text { quotidienne.. ») } \\
\text { - Un encart: « Les } \\
\text { municipales font la } \\
\text { République » } \\
\text { " Paris } \\
\text { réactionnaire " }\end{array}$ & $\begin{array}{l}\text { Analyse politique visant à } \\
\text { donner du sens à un } \\
\text { scrutin électoral. } \\
\text { (élections municipales 1971) }\end{array}$ \\
\hline \multirow[t]{3}{*}{1971} & $\begin{array}{l}\mathrm{n}^{\circ} 342 \\
\text { mai } 1971\end{array}$ & $\begin{array}{l}\text { «Élections: } \\
\text { modèle } 67 \text { modifié } \\
73 \text { » }\end{array}$ & $\begin{array}{ll}\text { Encart } & \\
\text { sur } & 2 \\
\text { pages } & \end{array}$ & « Événement » & Pas d'illustrations & $\begin{array}{l}\text { Analyse d'une situation } \\
\text { politique à partir du } \\
\text { Cahier } n^{\circ} 170 \text { de la FNSP } \\
\text { «Les élections de mars } \\
1967 \text { » }\end{array}$ \\
\hline & $\begin{array}{l}\mathrm{n}^{\circ} 364 \\
\text { novembre } \\
1971\end{array}$ & $\begin{array}{l}\text { «Histoire: la } \\
\text { République des } \\
\text { parricides» }\end{array}$ & 2 pages & Laspe & 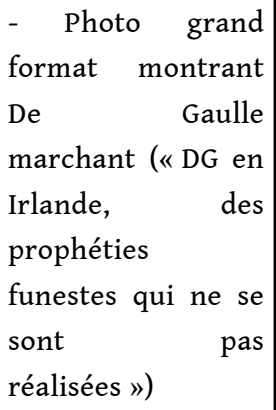 & $\begin{array}{l}\text { Compte rendu de } \\
\text { ouvrages: } \\
\text { - Viansson-Ponté P., } \\
\text { Histoire de la République } \\
\text { gaullienne, TII, Le temps des } \\
\text { orphelins, Fayard } \\
\text { - J.-R. Tournoux, Jamais } \\
\text { Dit, Plon }\end{array}$ \\
\hline & $\begin{array}{l}\mathrm{n}^{\circ} 370 \\
\text { décembre } \\
1971\end{array}$ & $\begin{array}{l}\text { "Histoire : CRS } \\
\text { avec nous!" }\end{array}$ & 1 page & Laspe & 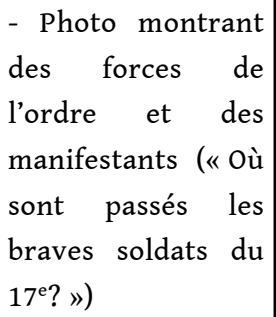 & $\begin{array}{l}\text { Compte rendu } \\
\text { d'ouvrage: } \\
\text { - M. Agulhon et F. Barrat, } \\
\text { CRS à Marseille (1944-1947), } \\
\text { A. Colin }\end{array}$ \\
\hline \multirow[t]{2}{*}{1972} & $\begin{array}{l}\mathrm{n}^{\circ} 373 \\
\text { janvier } \\
1972\end{array}$ & $\begin{array}{l}\text { «Opinion: un } \\
\text { vieux ménage " }\end{array}$ & 1 page & Laspe & Pas d'illustration & $\begin{array}{l}\text { Compte rendu } \\
\text { d'ouvrage: } \\
\text { - J. Charlot Les Français et } \\
\text { De Gaulle, IFOP }\end{array}$ \\
\hline & $\begin{array}{l}\mathrm{n}^{\circ} 405 \\
\text { août } 1972\end{array}$ & $\begin{array}{l}\text { «Essai : } \\
\text { boussoles } \\
\text { Duverger» }\end{array}$ & 1 page & Laspe & $\begin{array}{lr}\text { - Photo } & \text { M. } \\
\text { Duverger } & \text { («Un } \\
\text { pessimisme } & \text { bien } \\
\text { tempéré ») } & \end{array}$ & $\begin{array}{l}\text { Compte rendu } \\
\text { d'ouvrage: } \\
\text { - M. Duverger, Janus, les } \\
\text { deux faces de l'occident, } \\
\text { Fayard. }\end{array}$ \\
\hline
\end{tabular}




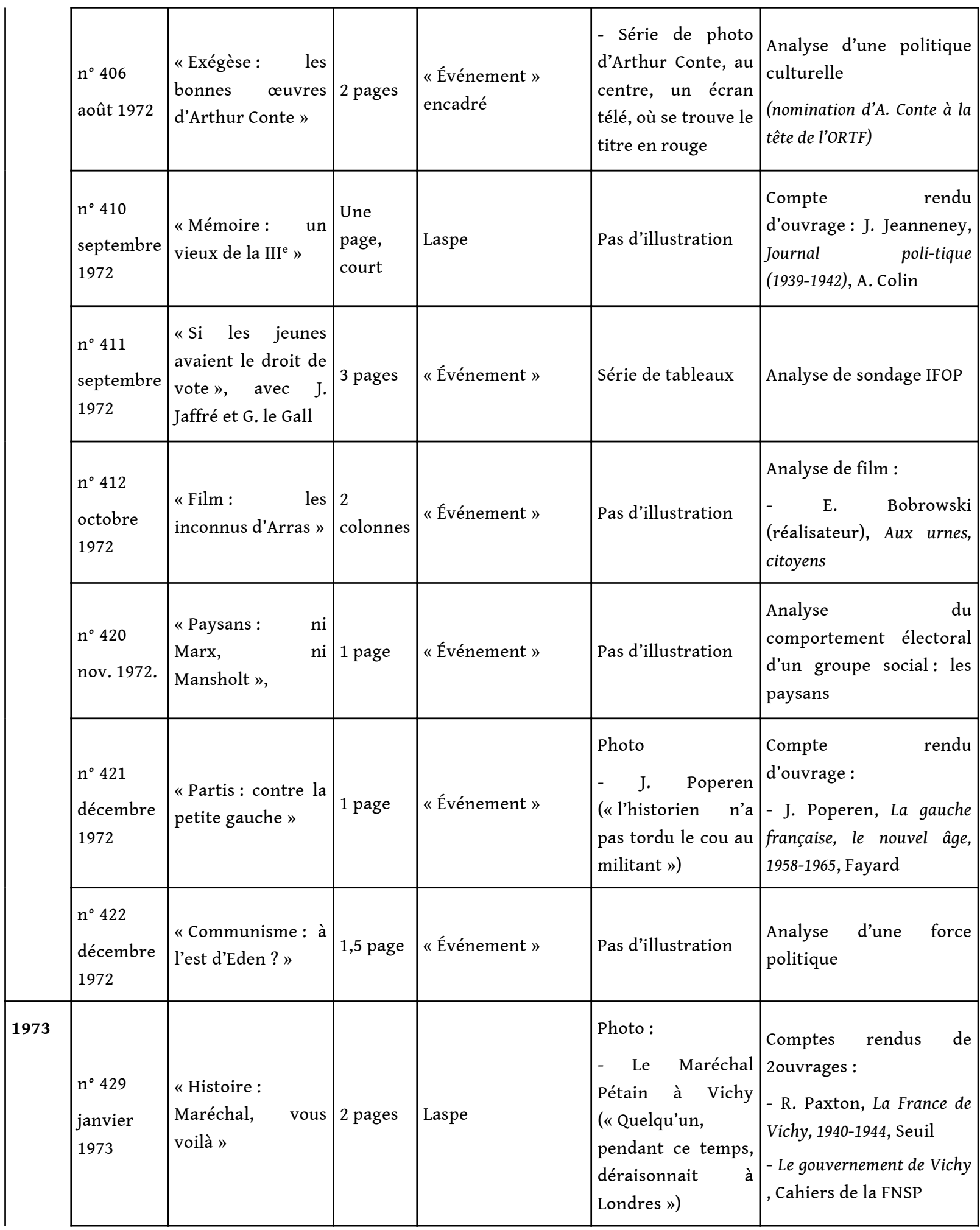




\begin{tabular}{|c|c|c|c|c|c|}
\hline $\begin{array}{l}n^{\circ} 430 \\
\text { février } \\
1973\end{array}$ & $\begin{array}{l}\text { «La gauche avec } \\
\text { des « si »» }\end{array}$ & 5 pages & $\begin{array}{l}\text { «Événement " } \\
\text { «Elections » } \\
\text { encadré }\end{array}$ & $\begin{array}{l}\text { - Dessin de Wiaz } \\
\text { (plusieurs hommes } \\
\text { politiques sur une } \\
\text { planche, } \\
\text { équilibre sur une } \\
\text { urne) } \\
\text { - Tableaux, photo.. }\end{array}$ & $\begin{array}{l}\text { Analyse de sociologie } \\
\text { politique } \\
\text { (élections législatives 1973, } \\
\text { avant le } 1^{\text {er }} \text { tour) }\end{array}$ \\
\hline $\begin{array}{l}n^{\circ} 432 \\
\text { février } \\
1973\end{array}$ & $\begin{array}{l}\text { «Prévisions: Une } \\
\text { chance sur deux » }\end{array}$ & 5 pages & «Événement » & - Tableaux & $\begin{array}{l}\text { Analyse de sociologie } \\
\text { politique (suite) } \\
\text { (élections législatives 1973, } \\
\text { avant le } 1^{\text {er }} \text { tour) }\end{array}$ \\
\hline $\begin{array}{l}\mathrm{n}^{\circ} 434 \\
\text { mars } 1973\end{array}$ & $\begin{array}{l}\text { «Une minorité } \\
\text { pour le président » }\end{array}$ & 3 pages & $\begin{array}{l}\text { « Notre } \\
\text { couverture» }\end{array}$ & - Dessin de Wiaz & $\begin{array}{l}\text { Analyse des résultats du } \\
\text { premier tour des } \\
\text { élections législatives } \\
\text { (élections législatives 1973,1 } \\
\text { er tour) }\end{array}$ \\
\hline $\begin{array}{l}\mathrm{n}^{\circ} 435 \\
\text { mars } 1973\end{array}$ & $\begin{array}{l}\text { «La France en } \\
\text { deux» }\end{array}$ & 3 pages & $\begin{array}{l}\text { «Notre } \\
\text { couverture " } \\
\text { «spécial élections» }\end{array}$ & - Tableaux & $\begin{array}{l}\text { Analyse des résultats du } \\
\text { deuxième tour des } \\
\text { élections législatives } \\
\text { (élections législatives } 1973,2 \\
{ }^{e} \text { tour) }\end{array}$ \\
\hline $\begin{array}{l}\mathrm{n}^{\circ} 446 \\
\text { mai } 1973\end{array}$ & $\begin{array}{ll}\text { «Exclusif: } & \text { les } \\
\text { secrets } & \text { de } \\
\text { l'isoloir } & \end{array}$ & 4 pages & «Événement » & $\begin{array}{l}\text { Plusieurs tableaux, } \\
\text { dessins, photos }\end{array}$ & $\begin{array}{l}\text { Analyse d'un sondage de } \\
\text { la Sofres sur les récentes } \\
\text { élections législatives } \\
\text { («sondage } \\
\text { postélectoral ») } \\
\text { (élections législatives 1973, } \\
\text { après le } 2^{e} \text { tour) }\end{array}$ \\
\hline $\begin{array}{l}\mathrm{n}^{\circ} 452 \\
\text { juillet } \\
1973\end{array}$ & $\begin{array}{l}\text { «Élections : la } \\
\text { vieille frontière " }\end{array}$ & 1 page & " Événement » & Pas d'illustrations & $\begin{array}{l}\text { Compte rendu } \\
\text { d'ouvrage: } \\
\text { - J. Charlot, Quand la } \\
\text { gauche peut gagner, } \\
\text { Moreau }\end{array}$ \\
\hline $\begin{array}{l}\mathrm{n}^{\circ} 457 \\
\text { août } 1973\end{array}$ & $\begin{array}{l}\text { "Essai : une statue } \\
\text { de mot» }\end{array}$ & 1 page & Laspe & $\begin{array}{l}\text { Photo: } \\
\text { - Le général De } \\
\text { Gaulle pendant un } \\
\text { discours («Un } \\
\text { acteur qui a connu } \\
\text { des «fours ») }\end{array}$ & $\begin{array}{l}\text { Compte rendu } \\
\text { d'ouvrage: } \\
\text { - I et S. Hoffman, Le style } \\
\text { du général de Gaulle, artiste } \\
\text { de la politique, Le Seuil. }\end{array}$ \\
\hline $\begin{array}{l}\mathrm{n}^{\circ} 460 \\
\text { septembre } \\
1973\end{array}$ & $\begin{array}{l}\text { «Un secret bien } \\
\text { gardé : l'argent » }\end{array}$ & 8 pages & \begin{tabular}{|lrr} 
"Notre & & \\
couverture " & "Les \\
Français et & le \\
bonheur » & &
\end{tabular} & $\begin{array}{l}-4 \text { pages de } \\
\text { tableaux } \\
\text { - Dessins de Siné }\end{array}$ & $\begin{array}{l}\text { Analyse de sondage } \\
\text { Sofres }\end{array}$ \\
\hline
\end{tabular}




\begin{tabular}{|c|c|c|c|c|}
\hline $\begin{array}{l}\text { «Jugez vos } \\
\text { patrons » }\end{array}$ & $\begin{array}{l}2,5 \\
\text { pages }\end{array}$ & $\begin{array}{ll}\text { Notre } & \text { couverture } \\
\text { («Le prix d'un } & \text { Le } \\
\text { Français ») } & \end{array}$ & $\begin{array}{lr}-\quad \text { Photo d'un } \\
\text { patron avec un } \\
\text { viseur sur lui } \\
\text { - Tableaux du } \\
\text { sondage } \\
\text { - encart: les } \\
\text { réactions d'un } \\
\text { patron et d'un } \\
\text { syndicaliste }\end{array}$ & $\begin{array}{l}\text { Analyse de sondage } \\
\text { Sofres }\end{array}$ \\
\hline $\begin{array}{l}\text { "Communisme: } \\
\text { Staline malgré } \\
\text { tout» }\end{array}$ & 2 pages & Laspe & $\begin{array}{l}\text { - Photo: portrait } \\
\text { de Staline }\end{array}$ & $\begin{array}{l}\text { Comptes rendus } \\
\text { d'ouvrage: } \\
\text { - L. Althusser, Réponse à J. } \\
\text { Lewis, Maspero } \\
\text { - J. Ellenstein, Le } \\
\text { socialisme dans un seul } \\
\text { pays, éd. Sociales } \\
\text { - G. Marchais, Le défi } \\
\text { démocratique, Grasset }\end{array}$ \\
\hline $\begin{array}{l}\text { «Tribune: une si } \\
\text { jolie petite } \\
\text { constitution" }\end{array}$ & 1 page & Événement & - Photo J. Ozouf & $\begin{array}{l}\text { Analyse constitutionnelle } \\
\text { à partir de la critique } \\
\text { d'un ouvrage de Guy } \\
\text { Mollet (La constitution de } \\
\text { 1958, A. Michel) }\end{array}$ \\
\hline $\begin{array}{ll}\text { «Congrès : la } \\
\text { bataille des } \\
\text { enseignants }\end{array}$ & $\begin{array}{l}2,5 \\
\text { pages }\end{array}$ & $\begin{array}{l}\text { "Notre } \\
\text { couverture }\end{array}$ & $\begin{array}{l}\text { - Un tableau } \\
\text { - Un encart }\end{array}$ & (congrès de la FEN) \\
\hline $\begin{array}{l}\text { "Témoignage : un } \\
\text { enseignement } \\
\text { dévalorisé » }\end{array}$ & $\begin{array}{l}\text { Encart } \\
\text { d'1 page }\end{array}$ & $\begin{array}{l}\text { «Notre époque » } \\
\text { ( « Où sont passés } \\
\text { les maîtres d'école? } \\
\text { ») }\end{array}$ & $\begin{array}{l}\text { Photos de deux des } \\
\text { auteurs: } \\
\text { - Huguette Bastide } \\
\text { (« Huguette } \\
\text { Bastide et ses } \\
\text { enfants. L'histoire } \\
\text { d'un } \\
\text { ressentiment. ») } \\
\text { - Danielle Granet } \\
\text { («Une élue sur } \\
\text { quinze».) }\end{array}$ & $\begin{array}{l}\text { Compte rendu de } \\
\text { témoignages } \\
\text { d'institutrices : } \\
\text { - D. Granet, Journal d'une } \\
\text { institutrice, J.C Lattès } \\
\text { - H. Bastide, Institutrice de } \\
\text { village, Denoël } \\
\text { - J. Rousselle, Être } \\
\text { institutrice, Du Cerf }\end{array}$ \\
\hline $\begin{array}{l}\text { «Spécial } \\
\text { éducation: Joseph } \\
\text { Fontanet défend sa } \\
\text { réforme" }\end{array}$ & $\begin{array}{l}2,5 \\
\text { pages }\end{array}$ & $\begin{array}{l}\text { «Notre époque " } \\
\text { «Spécial } \\
\text { enseignement }\end{array}$ & $\begin{array}{l}\text { - } 2 \text { Photos de J. } \\
\text { Fontanet («Le } \\
\text { problème n'est pas } \\
\text { d'entrer } \\
\text { l'Université, mais } \\
\text { d'en sortir avec un } \\
\text { diplôme ») }\end{array}$ & $\begin{array}{l}\text { Entretien avec le } \\
\text { ministre de l'éducation } \\
\text { nationale } \\
\text { (réforme scolaire) }\end{array}$ \\
\hline
\end{tabular}




\begin{tabular}{|c|c|c|c|c|c|}
\hline idem & $\begin{array}{l}\text { "Comment on } \\
\text { fabrique en France } \\
\text { l'image idéale de } \\
\text { l'homme" }\end{array}$ & $\begin{array}{l}3 \text { pages } \\
\text { (coupées } \\
\text { par des } \\
\text { pubs) }\end{array}$ & $\begin{array}{l}\text { «Dossier de la } \\
\text { semaine } \\
\text { («Ceux qui raconte } \\
\text { notre histoire ») }\end{array}$ & $\begin{array}{|lr|}\text { - Photo : } & \text { un groupe } \\
\text { d'élus } & \text { ( } \\
\text { sans } & \text { Chabaux- } \\
\text { sans } & \text { Chaban } \\
\text { Delmas } & \end{array}$ & $\begin{array}{l}\text { Compte rendu } \\
\text { d'ouvrage: } \\
\text { - J. Lagroye, Société et } \\
\text { politique: J. Chaban Delmas } \\
\text { à Bordeaux, Pédrône }\end{array}$ \\
\hline idem & $\begin{array}{l}\text { «Des élus sur } \\
\text { mesure» }\end{array}$ & $\begin{array}{l}2 \text { pages } \\
\text { (coupées } \\
\text { par des } \\
\text { pubs) }\end{array}$ & idem & Pas d'illustration & $\begin{array}{l}\text { Compte rendu } \\
\text { d'ouvrage: } \\
\text { - P. Weill, D. Lindon, Le } \\
\text { choix d'un député - un } \\
\text { modèle explicatif du } \\
\text { comportement électoral», } \\
\text { Minuit MinuitMinuit }\end{array}$ \\
\hline $\begin{array}{l}n^{\circ} 483 \\
\text { février } \\
1974\end{array}$ & Pas de titre & 1 page & $\begin{array}{l}\text { Laspe } \\
\text { («d'un auteur } \\
\text { l'autre ») }\end{array}$ & $\begin{array}{l}-\quad \text { Photo d'Alain } \\
\text { Krivine }\end{array}$ & $\begin{array}{l}\text { Compte-rendu } \\
\text { d'ouvrage: } \\
\text { - A. Krivine, Questions sur } \\
\text { la révolution, Stock }\end{array}$ \\
\hline $\begin{array}{l}\mathrm{n}^{\circ} 486 \\
\text { mars } 1974\end{array}$ & 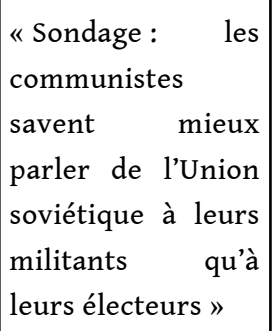 & 2 pages & «Événement » & 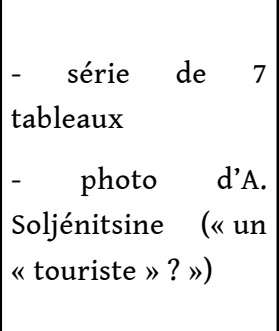 & $\begin{array}{l}\text { Analyse de sondage } \\
\text { Sofres }\end{array}$ \\
\hline $\begin{array}{l}\mathrm{n}^{\circ} 487 \\
\text { mars } 1974\end{array}$ & $\begin{array}{l}\text { «Ce que les } \\
\text { Français pensent } \\
\text { de la gauche au } \\
\text { pouvoir " }\end{array}$ & 2 pages & $\begin{array}{l}\text { « Notre } \\
\text { couverture» }\end{array}$ & $\begin{array}{l}- \text { Tableaux } \\
-\quad \text { Encarts } \\
\text { (« restriction } \\
\text { mentale»; «plus } \\
\text { les jeunes que les } \\
\text { femmes») }\end{array}$ & $\begin{array}{l}\text { Analyse de sondage } \\
\text { Sofres }\end{array}$ \\
\hline $\begin{array}{l}\mathrm{n}^{\circ} 491 \\
\text { avril } 1974\end{array}$ & $\begin{array}{ll}\text { "Un fils } \\
\text { d' « instit » }\end{array}$ & $\begin{array}{l}\text { Encart } \\
\text { qui } \\
\text { traverse } \\
\text { deux } \\
\text { pages }\end{array}$ & «Événement » & Pas d'illustration & $\begin{array}{l}\text { Biographie de Pompidou } \\
\text { (Mort de Pompidou) }\end{array}$ \\
\hline $\begin{array}{l}\mathrm{n}^{\circ} 492 \\
\text { avril } 1974\end{array}$ & $\begin{array}{l}\text { «Le tiercé du } 5 \\
\text { mai » }\end{array}$ & 2 pages & $\begin{array}{l}\text { "Événement » "- } \\
\text { spécial élections " }\end{array}$ & 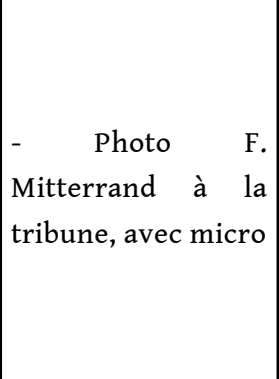 & $\begin{array}{l}\text { Analyse de sondage } \\
\text { politique et des résultats } \\
\text { des premiers tours des } \\
\text { élections présidentielles } \\
\text { et législatives depuis } \\
1962 \\
\text { (Élections prés. 1974, av. } \\
\text { le } 1^{\text {er }} \text { tour) }\end{array}$ \\
\hline
\end{tabular}




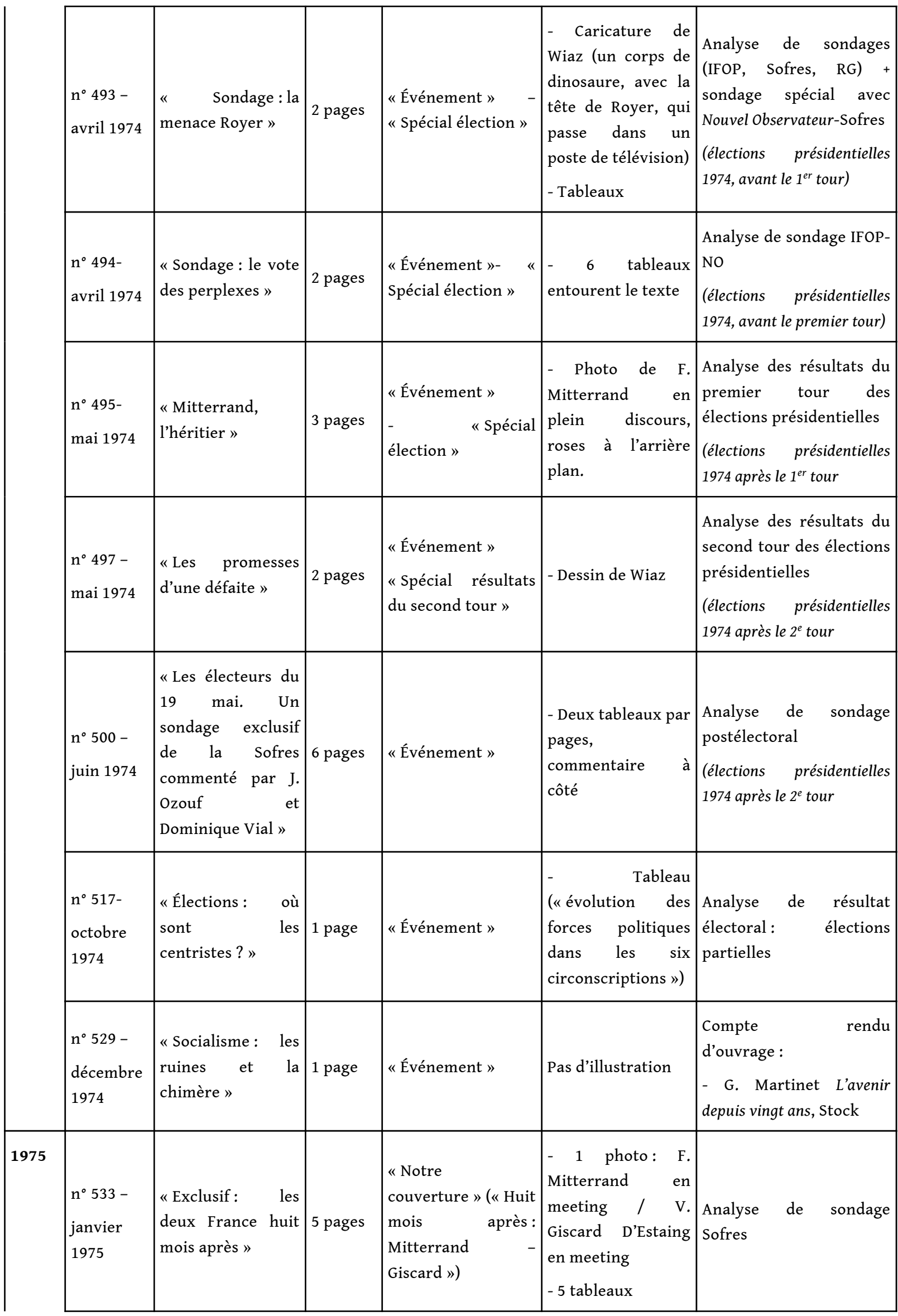




\begin{tabular}{|c|c|c|c|c|c|}
\hline $\begin{array}{l}n^{\circ} 534- \\
\text { février } \\
1975\end{array}$ & $\begin{array}{l}\text { "Sociologie: les } \\
\text { socialistes au } \\
\text { rayon X (avec } \\
\text { Jérôme Jaffré) }\end{array}$ & 2 pages & «Événement » & $\begin{array}{l}\text { - Photo: À la } \\
\text { tribune du congrès } \\
\text { de Pau : C Estier, P. } \\
\text { Mauroy, F. } \\
\text { Mitterrand } \\
\text { ( Comment } \\
\text { « ancrer à gauche » } \\
\text { les nouvelles } \\
\text { recrues?») } \\
\text { Encart (Le choix du } \\
\text { peuple socialiste) }\end{array}$ & $\begin{array}{l}\text { Analyse de sondage } \\
\text { Sofres }\end{array}$ \\
\hline $\begin{array}{l}n^{\circ} 534- \\
\text { février } \\
1975\end{array}$ & $\begin{array}{l}\text { «Des recettes } \\
\text { pour la gauche » }\end{array}$ & 2 pages & Laspe & $\begin{array}{l}2 \text { Photos: } \\
\text { - A Laurens p. } 57 \\
\text { (« Nous avons tous } \\
\text { beaucoup vieilli ») } \\
\text {-J.P. Cot ( Aucune } \\
\text { concession à la } \\
\text { mode ») }\end{array}$ & $\begin{array}{l}\text { Comptes rendus } \\
\text { d'ouvrage: } \\
\text { - A. Laurens, D'une France } \\
\text { à l'autre, Gallimard } \\
\text { - R.G. Schwartzenberg } \\
\text { Sociologie politique, } \\
\text { Montchrestien } \\
\text { - J.P Cot, J.P. Mounier, } \\
\text { Pour une sociologie } \\
\text { politique, Seuil }\end{array}$ \\
\hline $\begin{array}{l}\mathrm{n}^{\circ} 540- \\
\text { mars } 1975\end{array}$ & $\begin{array}{l}\text { «Enseignement: } \\
\text { les ombres de la } \\
\text { réforme Haby" }\end{array}$ & 3 pages & $\begin{array}{l}\text { « Notre } \\
\text { couverture» }\end{array}$ & $\begin{array}{l}\text { - Photo : Réunion } \\
\text { d'étudiants } \\
\text { protestataires au } \\
\text { centre Jussieu (" Il } \\
\text { y a déjà eu } \\
\text { tellement a de } \\
\text { réformes qu’on ne } \\
\text { croit plus à } \\
\text { aucune.») }\end{array}$ & $\begin{array}{l}\text { Interview de J.-C } \\
\text { Casanova et A. Prost } \\
\text { menée par J. Ozouf et F. } \\
\text { Furet }\end{array}$ \\
\hline $\begin{array}{l}\mathrm{n}^{\circ} 541- \\
\text { mars } 1975\end{array}$ & $\begin{array}{l}\text { «Staline à tous les } \\
\text { temps» }\end{array}$ & 2 pages & $\begin{array}{l}\text { «Document de la } \\
\text { semaine» } \\
\text { «Histoire: } 9 \text { clefs } \\
\text { pour le présent» }\end{array}$ & Photo J. Ozouf & $\begin{array}{l}\text { Comptes rendus de } 6 \\
\text { ouvrages sur la question }\end{array}$ \\
\hline $\begin{array}{l}\mathrm{n}^{\circ} 549- \\
\text { mai } 1975\end{array}$ & $\begin{array}{l}\text { «Élections: le } \\
\text { baromètre des } \\
\text { «partielles»» }\end{array}$ & 1 page & "Événement » & $\begin{array}{l}\text { - Photo J. Limouzy } \\
\text { («Un test pour } \\
\text { Chirac ») }\end{array}$ & $\begin{array}{l}\text { Analyse de résultats } \\
\text { d'élections partielles }\end{array}$ \\
\hline $\begin{array}{l}\mathrm{n}^{\circ} 550- \\
\text { mai } 1975\end{array}$ & $\begin{array}{l}\text { «Maurice Thorez, } \\
\text { fils du Parti » }\end{array}$ & 6 pages & $\begin{array}{l}\text { «Document de la } \\
\text { semaine» }\end{array}$ & - Photos & $\begin{array}{l}\text { Interview de Philippe } \\
\text { Robrieux, auteur d'une } \\
\text { biographie de M. Thorez, } \\
\text { menée par J. Ozouf et } \\
\text { J.Alia }\end{array}$ \\
\hline
\end{tabular}




\begin{tabular}{|c|c|c|c|c|c|}
\hline $\begin{array}{l}\mathrm{n}^{\circ} 552- \\
\text { juin } 1975\end{array}$ & $\begin{array}{l}\text { "Pouvoir: } \\
\text { Poniatowski et le } \\
\text { futur» }\end{array}$ & $\begin{array}{ll}3 / 4 & \text { de } \\
\text { page } & \end{array}$ & $\begin{array}{l}\text { "Événement " } \\
\text { Rubrique «on en } \\
\text { parlera demain " }\end{array}$ & Pas d'illustration & $\begin{array}{l}\text { Compte } \\
\text { d'ouvrage: } \\
-\quad \text { M. } \\
\text { Conduire le chandu } \\
\text { Essai sur le pouvoir, } \\
\text { Fayard. }\end{array}$ \\
\hline $\begin{array}{l}\mathrm{n}^{\circ} 553- \\
\text { juin } 1975\end{array}$ & $\begin{array}{ll}\text { "Élections: les } \\
\text { habits neufs de } \\
\text { l'UDR» }\end{array}$ & 1 page & " Événement » & 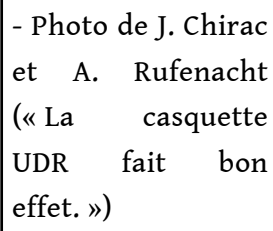 & 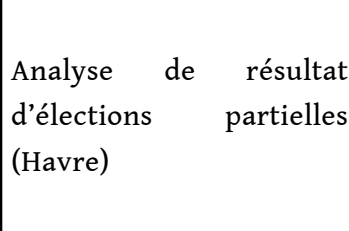 \\
\hline $\begin{array}{l}\mathrm{n}^{\circ} 567- \\
\text { septembre } \\
1975\end{array}$ & $\begin{array}{l}\text { «Analyse : } \\
\text { l'immuable } \\
\text { boussole du PC » }\end{array}$ & 2 pages & Laspe & $\begin{array}{l}\text { Deux photos: } \\
\text { - Enterrement de } \\
\text { M. Thorez en } 1964 \\
\text { («Pour qui sait } \\
\text { voir, les choses } \\
\text { changent») } \\
\text { - Duclos, Fabre, } \\
\text { Marchais, } \\
\text { Mitterrand au } \\
\text { meeting de la } \\
\text { gauche unie (déc. } \\
\text { 1972) (" Le rapport } \\
\text { de force est devenu } \\
\text { la question } \\
\text { politique } \\
\text { capitale ») }\end{array}$ & $\begin{array}{l} \\
\\
\text { Compte-rendu } \\
\text { d'ouvrage : } \\
\text { - E. Fajon L'Union est un } \\
\text { combat, Éditions sociales }\end{array}$ \\
\hline $\begin{array}{l}\mathrm{n}^{\circ} 569- \\
\text { septembre } \\
1975\end{array}$ & $\begin{array}{l}\text { "Enquête : } \\
\text { l'auberge } \\
\text { espagnole» }\end{array}$ & 1 page & Laspe & Pas d'illustration & $\begin{array}{l}\text { Compte rendu } \\
\text { d'ouvrage: } \\
\text { - A., Andrieu, J.-L. } \\
\text { Mingalon L'adhésion des } \\
\text { nouveaux communistes de } \\
\text { 1975, Calmann-Lévy. }\end{array}$ \\
\hline $\begin{array}{l}\mathrm{n}^{\circ} \quad 571 \\
\text { octobre } \\
1975\end{array}$ & $\begin{array}{l}\text { "Châtellerault: } \\
\text { les surprises d'une } \\
\text { élection ", avec F } \\
\text { Olivier-Giesbert }\end{array}$ & 1,5 page & $\begin{array}{l}\text { "Notre } \\
\text { couverture» }\end{array}$ & $\begin{array}{l}\text { - Photo: Chirac, } \\
\text { Monory, } \\
\text { Poniatowski et à } \\
\text { Abelin statues } \\
\text { Châtellerault. } \\
\text { ("Des dableau : } \\
\text { ébranlées ") } \\
\text { - } \\
\text { comparaison } \\
\text { résultats } \\
\text { sondages } \\
\text { 1973-1975 }\end{array}$ & $\begin{array}{l}\text { Analyse d'un résultat } \\
\text { d'élections partielles } \\
\text { dans une circonscription } \\
\text { symbolique. }\end{array}$ \\
\hline
\end{tabular}




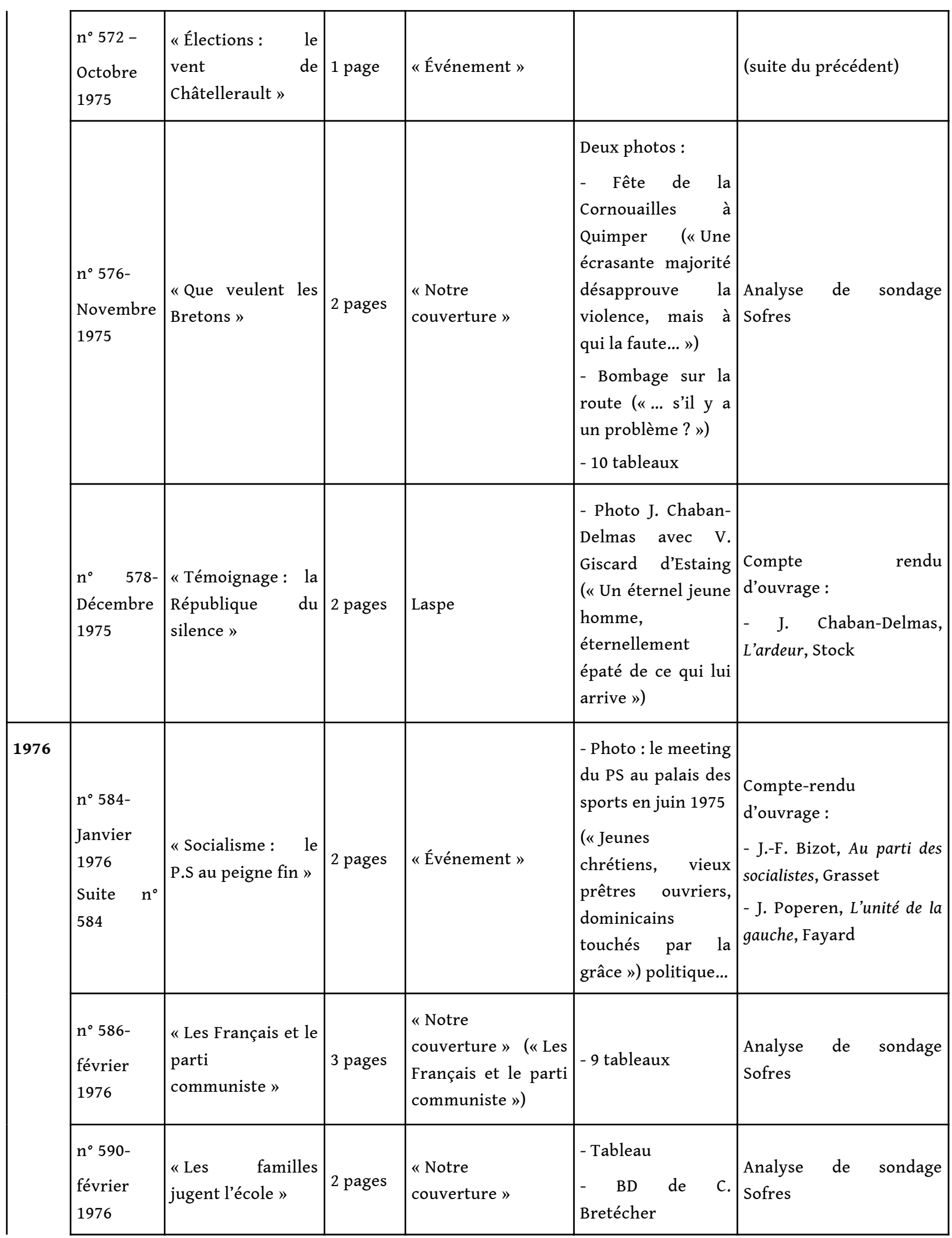




\begin{tabular}{|c|c|c|c|c|c|}
\hline $\begin{array}{l}\mathrm{n}^{\circ} 591- \\
\text { mars } 1976\end{array}$ & $\begin{array}{l}\text { «Clefs pour les } \\
\text { cantonales» }\end{array}$ & 1 page & $\begin{array}{l}\text { « Notre } \\
\text { couverture» }\end{array}$ & $\begin{array}{l}\text { - Photo: Une } \\
\text { discussion avec le } \\
\text { maire, dans le } \\
\text { bistrot d'un chef } \\
\text { lieu de canton (« } \\
\text { Sous le } \\
\text { domestique, } \\
\text { découvrir } \\
\text { politique »). }\end{array}$ & $\begin{array}{l}\text { Explication et intérêt des } \\
\text { élections cantonales } \\
\text { (élections cantonales 1976) }\end{array}$ \\
\hline $\begin{array}{l}\mathrm{n}^{\circ} 592- \\
\operatorname{mars} 1976\end{array}$ & $\begin{array}{ll}\text { «Élections: } & \text { un } \\
\text { parlement } & \text { de } \\
\text { rêve » } & \end{array}$ & 2 pages & $\begin{array}{l}\text { « Notre } \\
\text { couverture» }\end{array}$ & $\begin{array}{l}- \text { Photo } \\
-3 \text { tableaux } \\
-1 \text { encart (« un } \\
\text { étonnement: les } \\
\text { sièges } \\
\text { communistes ») }\end{array}$ & $\begin{array}{l}\text { Jeu politique } \\
\text { (élections cantonales 1976) }\end{array}$ \\
\hline $\begin{array}{l}\text { Suite } \quad \mathrm{n}^{\circ} \\
592\end{array}$ & $\begin{array}{l}\text { «Essai : pas de } \\
\text { roses } \\
\text { Lénine" }\end{array}$ & 1 page & Laspe & $\begin{array}{l}\text { Photo: A. } \\
\text { Besançon (« Un } \\
\text { appel à toutes les } \\
\text { autorités } \\
\text { occidentales ») }\end{array}$ & $\begin{array}{l}\text { Compte rendu } \\
\text { d'ouvrage: } \\
\text { - A. Besançon, Court traité } \\
\text { de soviétologie à l'usage des } \\
\text { autorités civiles, militaires } \\
\text { et religieuses, Hachette }\end{array}$ \\
\hline $\begin{array}{l}\mathrm{n}^{\circ} 593- \\
\operatorname{mars} 1976\end{array}$ & $\begin{array}{l}\text { «Élections: les } \\
\text { quatre familles des } \\
\text { deux France " }\end{array}$ & 2 pages & «Événement» & $\begin{array}{lr}\text { - Photo : } & \text { M. } \\
\text { Poniatowski } & \text { ( } \\
\text { Des } \\
\text { électeurs } & \text { de } \\
\text { mauvaise } & \\
\text { humeur ») } & \end{array}$ & $\begin{array}{l}\text { Analyse des résultats du } \\
\text { second tour des } \\
\text { cantonales } \\
\text { (élections cantonales 1976) }\end{array}$ \\
\hline $\begin{array}{l}\mathrm{n}^{\circ} 594- \\
\text { mars } 1976\end{array}$ & $\begin{array}{l}\text { «Témoignage: la } \\
\text { flamme de Pierre } \\
\text { Brossolette» }\end{array}$ & 1 page & « Notre époque» & $\begin{array}{l}\text { - Photo: P. } \\
\text { Brossolette } \\
\text { («Un destin } \\
\text { politique } \\
\text { exemplaire») }\end{array}$ & $\begin{array}{l}\text { Compte rendu } \\
\text { d'ouvrage: } \\
\text { - G. Brossolette, Il } \\
\text { s'appelait Pierre Brossolette, } \\
\text { A. Michel }\end{array}$ \\
\hline $\begin{array}{l}\mathrm{n}^{\circ} 595- \\
\text { avril } 1976\end{array}$ & $\begin{array}{lr}\text { «Sondage: } & \text { les } \\
\text { Français } & \mathrm{y} \\
\text { croient } & \end{array}$ & 1 page & $\begin{array}{l}\text { «Événement» } \\
\text { Rubrique «on en } \\
\text { parlera demain » }\end{array}$ & - 2 tableaux & $\begin{array}{l}\text { Analyse de sondage } \\
\text { Sofres }\end{array}$ \\
\hline $\begin{array}{l}\mathrm{n}^{\circ} 604- \\
\text { juin } 1976\end{array}$ & $\begin{array}{l}\text { "Mémoire : le } \\
\text { rêve et la passion " }\end{array}$ & 1 page & «Événement » & $\begin{array}{l}-\quad \text { Photo A. } \\
\text { Sanguinetti («Un } \\
\text { appel } \\
\text { nostalgique ») }\end{array}$ & $\begin{array}{l}\text { Compte rendu } \\
\text { d'ouvrage: } \\
\text { - Sanguinetti A., Une } \\
\text { nouvelle résistance, Plon }\end{array}$ \\
\hline $\begin{array}{l}\mathrm{n}^{\circ} 606- \\
\text { juin } 1976\end{array}$ & $\begin{array}{ll}\text { «Sondage : } & \text { ces } \\
\text { électeurs } & \text { qui } \\
\text { ébranlèrent } & \\
\text { l'Élysée » } & \end{array}$ & 6 pages & $\begin{array}{l}\text { «Document de la } \\
\text { semaine» }\end{array}$ & -8 tableaux & $\begin{array}{l}\text { Analyse de sondage } \\
\text { postélectoral Sofres }\end{array}$ \\
\hline
\end{tabular}




\begin{tabular}{|c|c|c|c|c|c|}
\hline $\begin{array}{l}\mathrm{n}^{\circ} 607- \\
\text { juin } 1976\end{array}$ & $\begin{array}{l}\text { "Deux mots qui } \\
\text { font encore peur » }\end{array}$ & $1 / 2$ page & $\begin{array}{l}\text { Laspe } \\
\text { «Spécial front } \\
\text { populaire » }\end{array}$ & Pas d'illustration & $\begin{array}{l}\text { Analyse de manuels } \\
\text { scolaires contemporains }\end{array}$ \\
\hline $\begin{array}{l}\mathrm{n}^{\circ} 616- \\
\text { août } 1976\end{array}$ & $\begin{array}{l}\text { "Sondage : ceux } \\
\text { qui regrettent } \\
\text { Chirac" }\end{array}$ & 2 pages & «Événement » & $\begin{array}{l}\text { - Photo: J. Chirac } \\
\text { aux journées } \\
\text { parlementaires de } \\
\text { l'UDR, en sept. } \\
1975 \text { (« Un quitus } \\
\text { nuancé ») } \\
\text { - } 4 \text { tableaux }\end{array}$ & $\begin{array}{l}\text { Analyse de sondage } \\
\text { Sofres }\end{array}$ \\
\hline $\begin{array}{l}\mathrm{n}^{\circ} 619- \\
\text { septembre } \\
1976\end{array}$ & $\begin{array}{ll}\text { "Partis: } & \text { les } \\
\text { croisés de } & \text { la } \\
\text { politique } & \end{array}$ & 2 pages & «Événement » & $\begin{array}{llr} & & \\
-\quad \text { Photo: } & \text { une } \\
\text { militante } & & \text { des } \\
\text { jeunesses } & \\
\text { communiste } & \text { " Se } \\
\text { méfier de } & \text { la } \\
\text { psychologie } & \text { et } & \text { de } \\
\text { la morale ») } & \end{array}$ & $\begin{array}{l}\text { Compte rendu } \\
\text { d'ouvrage: } \\
\text { - Y., Bourdet, Qu'est-ce qui } \\
\text { fait courir les militants, } \\
\text { Stock } \\
\text { - J., Lagroye, G. Lords, Les } \\
\text { militants politiques dans } \\
\text { trois partis français (PC, PS, } \\
\text { UDR), Pédrône }\end{array}$ \\
\hline $\begin{array}{l}\mathrm{n}^{\circ} 621- \\
\text { octobre } \\
1976\end{array}$ & $\begin{array}{l}\text { "Législatives: le } \\
\text { verdict des } \\
\text { chiffres" }\end{array}$ & 1 page & « Événement » & $\mid \begin{array}{lr}\text {-Photo: un bureau } \\
\text { de vote à } & \text { Paris } \\
\text { ( Une } & \text { vie } \\
\text { électorale qui ne } \\
\text { change que par } \\
\text { saccades») }\end{array}$ & $\begin{array}{l}\text { Analyse d'une situation } \\
\text { électorale } \\
\text { (élections législatives 1978) }\end{array}$ \\
\hline $\begin{array}{l}\mathrm{n}^{\circ} 625- \\
\text { octobre } \\
1976\end{array}$ & « Le verdict» & 5 pages & $\begin{array}{l}\text { « Notre Époque » } \\
\text { «La fortune des } \\
\text { Français » }\end{array}$ & $\begin{array}{l}-9 \text { tableaux } \\
-8 \text { dessins } \\
-1 \text { encart : «Cinq } \\
\text { règles pour un } \\
\text { sondage» }\end{array}$ & Analyse de sondage Crep \\
\hline $\begin{array}{l}\mathrm{n}^{\circ} \quad 627- \\
\text { novembre } \\
1976\end{array}$ & $\begin{array}{lr}\text { "Sondage: } & \text { la } \\
\text { boussole } & \text { des } \\
\text { municipale } & \end{array}$ & 1,5 page & «Événement » & -6 tableaux & $\begin{array}{l}\text { Analyse de sondage } \\
\text { Sofres } \\
\text { (élections } \\
\text { municipales 1977) }\end{array}$ \\
\hline $\begin{array}{l}\mathrm{n}^{\circ} 629- \\
\text { novembre } \\
1976\end{array}$ & $\begin{array}{ll}\text { "Élections: } & \text { le } \\
\text { désarroi de la } \\
\text { majorité » }\end{array}$ & 1 page & « Événement » & $\begin{array}{lr}\text { - Photo: le } & \text { nouvel } \\
\text { élu du PS } & \text { André } \\
\text { Poutissou. } & \text { («Un } \\
\text { dégel } & \text { des } \\
\text { abstentionnistes ») }\end{array}$ & $\begin{array}{l}\text { Analyse du second tour } \\
\text { des partielles }\end{array}$ \\
\hline
\end{tabular}




\begin{tabular}{|c|c|c|c|c|c|c|}
\hline & $\begin{array}{l}\mathrm{n}^{\circ} 630- \\
\text { décembre } \\
1976\end{array}$ & $\begin{array}{l}\text { «La boussole des } \\
\text { municipale (II)» }\end{array}$ & 1,5 page & « Événement » & 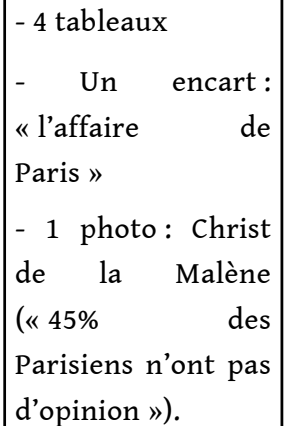 & $\begin{array}{l}\text { Analyse de sondage } \\
\text { Sofres } \\
\text { (élections municipales 1977) }\end{array}$ \\
\hline \multirow[t]{7}{*}{1977} & $\begin{array}{l}\mathrm{n}^{\circ} 634- \\
\text { janvier } \\
1977\end{array}$ & $\begin{array}{l}\text { «La boussole des } \\
\text { municipale (III)» }\end{array}$ & 1,5 page & « Événement » & - 7 tableaux & $\begin{array}{l}\text { Analyse de sondage } \\
\text { Sofres } \\
\text { (élections municipales 1977) }\end{array}$ \\
\hline & $\begin{array}{l}\mathrm{n}^{\circ} 638- \\
\text { janvier } \\
1977\end{array}$ & $\begin{array}{l}\text { «La boussole des } \\
\text { municipale (IV)» }\end{array}$ & 1,5 page & «Événement » & -6 tableaux & $\begin{array}{l}\text { Analyse de sondage } \\
\text { Sofres } \\
\text { (élections } \\
\text { municipales 1977) }\end{array}$ \\
\hline & $\begin{array}{l}n^{\circ} 639- \\
\text { février } \\
1977\end{array}$ & «L'électorat vert » & 1,5 page & " Événement » & $\begin{array}{l}\text { - Tableau: les } \\
\text { électeurs } \\
\text { écologistes à Paris }\end{array}$ & $\begin{array}{l}\text { Analyse de sondage } \\
\text { Sofres } \\
\text { (élections municipales 1977) }\end{array}$ \\
\hline & $\begin{array}{l}\mathrm{n}^{\circ} 640- \\
\text { Février } \\
1977\end{array}$ & $\begin{array}{l}\text { «Des électeurs } \\
\text { venus } \\
\text { «d'ailleurs» }\end{array}$ & 1 page & "Événement » & $\begin{array}{l}-\begin{array}{l}1 \\
\text { Photo : M. }\end{array} \\
\text { Jobert (« Du goût } \\
\text { pour la charade ») } \\
\text { - Tableau: } \\
\text { l'électorat de M. } \\
\text { Jobert à Paris }\end{array}$ & $\begin{array}{l}\text { Analyse de sondage } \\
\text { Sofres } \\
\text { (élections municipales 1977) }\end{array}$ \\
\hline & $\begin{array}{l}\mathrm{n}^{\circ} 641- \\
\text { Février } \\
1977\end{array}$ & $\begin{array}{l}\text { «La boussole des } \\
\text { municipale }(\mathrm{V}) »\end{array}$ & 1 page & "Événement» & -6 tableaux & $\begin{array}{l}\text { Analyse de sondage } \\
\text { Sofres } \\
\text { (élections municipales 1977) }\end{array}$ \\
\hline & $\begin{array}{l}\mathrm{n}^{\circ} 642- \\
\text { Février } \\
1977\end{array}$ & $\begin{array}{l}\text { «Et si la gauche } \\
\text { gagnait Paris?» }\end{array}$ & 3 pages & $\begin{array}{l}\text { «Notre } \\
\text { couverture» }\end{array}$ & 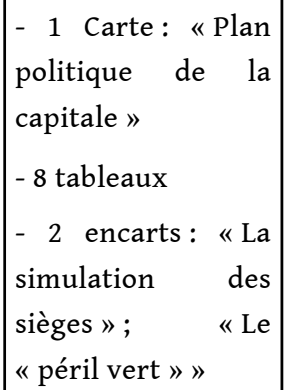 & $\begin{array}{l}\text { Analyse de sondage } \\
\text { Sofres } \\
\text { (élections municipales 1977) }\end{array}$ \\
\hline & $\begin{array}{l}\mathrm{n}^{\circ} 645- \\
\text { Mars } 1977\end{array}$ & $\begin{array}{l}\text { «La France } \\
\text { recommencée } "\end{array}$ & 4 pages & $\begin{array}{l}\text { «Notre } \\
\text { couverture» }\end{array}$ & $\begin{array}{l}\text { - Graphiques } \\
\text { - carte de France, } \\
\text { - Tableaux }\end{array}$ & $\begin{array}{l}\text { Analyse des résultats du } \\
\text { second tour des élections } \\
\text { (élections municipales 1977) }\end{array}$ \\
\hline
\end{tabular}




\begin{tabular}{|c|c|c|c|c|}
\hline $\begin{array}{ll}\text { «Information: la } \\
\text { rage des } \\
\text { sondages }\end{array}$ & 1 page & «Événement » & $\begin{array}{l}\text { - Photo : Le plateau } \\
\text { de TF1 le soir du } 13 \\
\text { mars («L'erreur } \\
\text { est de vouloir faire } \\
\text { parler les chiffres } \\
\text { au futur»). }\end{array}$ & $\begin{array}{lll}\text { Analyse } & \text { d'un } & \text { outil } \\
\text { d'analyse } & & \end{array}$ \\
\hline $\begin{array}{l}\text { "Sondage : le choc } \\
\text { des municipales» }\end{array}$ & 5 pages & « Événement » & $\begin{array}{l}- \text { Dessin } \\
-3 \text { encarts } \\
-7 \text { tableaux }\end{array}$ & $\begin{array}{l}\text { Analyse de sondage } \\
\text { postélectoral } \\
\text { (élections municipales 1977/ } \\
\text { élections législatives 1978) }\end{array}$ \\
\hline $\begin{array}{l}\text { «Mitterrand au } \\
\text { rendez-vous de } \\
\text { l'histoire», } \\
\text { Avec F. Furet }\end{array}$ & 3 pages & «Événement » & $\begin{array}{l}\text { - photo: Foule en } \\
\text { liesse devant le } \\
\text { siège du PS après } \\
\text { l'annonce de la } \\
\text { victoire ("Les } \\
\text { Français ont voté } \\
\text { sur le chômage, la } \\
\text { crise... et l'image } \\
\text { de Mitterrand ") } \\
\text { - } 2 \text { encarts : «Le } \\
\text { mécanisme } \\
\text { présidentiel ; } \\
\text { "Les résultats de } \\
\text { Paris" } \\
\text { - } 2 \text { cartes «La } \\
\text { France de gauche " } \\
\text { - établies au } \\
\text { CIREGE Paris X } \\
\text { Nanterre }\end{array}$ & $\begin{array}{l} \\
\\
\text { Analyse du résultat du } \\
\text { second tour des élections } \\
\text { présidentielles } \\
\text { (élections présidentielles } \\
\text { 1981, } 2^{e} \text { tour) }\end{array}$ \\
\hline
\end{tabular}

\section{NOTES}

1. Les articles de France-Observateur, où Jacques Ozouf entre en 1958, ne sont pas indiqués ici. Ils sont alors signés Jacques Vial. 